Cadernos de Clio, Curitiba, n. ${ }^{\circ}$ 2, 2011

\title{
Estudos sobre a Historiografia da Arqueologia Maia
}

Eduardo Teixeira Akiyama

Resumo: $O$ texto aqui apresentado é fruto de minha iniciação científica orientada pelos professores Doutores Pedro Paulo Abreu Funari e Alexandre Guida Navarro e financiada pela CNPq, edital $\mathrm{n}^{\circ}$ 01/2007, que vigorou de 01/10/2009 a 31/07/2010. O que buscaremos abaixo é uma análise arqueológica sobre os maias. Partiremos do chamado "modelo tradicional" de análise desta civilização, em voga dos anos 1930 aos 1970, aproximadamente, e da revisão desse modelo, que se fez de então. Passaremos por importantes aspectos - como o urbanismo, a guerra, o governo como teocracia ou Estado laico e a religião - buscando compreender a construção de padrões e de modelos a partir dos escritos dos maiores expoentes dessas duas correntes arqueológicas. Ressalto que a pesquisa não teve o intuito de refutar nenhuma das obras, mas expor os méritos e as limitações dos diferentes períodos, tais quais as tecnologias, os métodos arqueológicos e até as ideologias que influenciaram cada pesquisador.

Palavras-chave: maias, povos pré-colombianos, arqueologia.

\section{O Estudo da Historiografia}

A arqueologia maia foi inaugurada com duas explorações realizadas entre os anos de 1839 e 1841 pelo diplomata e advogado norte-americano John Stephens e o arquiteto inglês Frederick Catherwood (NAVARRO, 2008). Da exploração dos dois

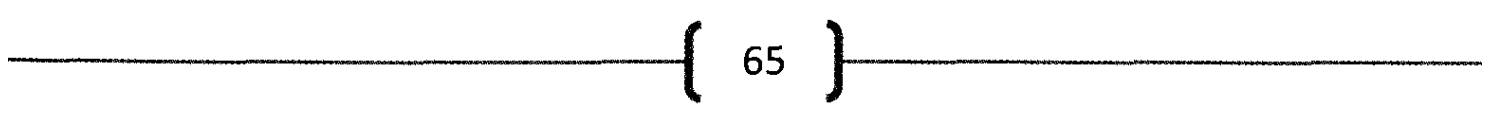


arqueólogos surgiram dois livros, respectivamente: Incidents of Travel in Central América, Chiapas and Yucatán (1841) e Incidents of Travel in Yucatán (1843), porém, por se encontrarem mergulhadas no imaginário e no contexto intelectual do século XIX, estas obras acabaram expressando uma natureza exótica da civilização maia através de desenhos artísticos e fantasiosos de templos e monumentos em geral.

A partir das possibilidades inauguradas pelos dois pioneiros, ao final do mesmo século, vários arqueólogos continuaram a se aventurar, a descrever e a delimitar novos sítios arqueológicos maias, tais como Alice e Augustus Le Plongeon, Desiré Charnay, Sylvanus G. Morley, Edward H. Thompson e Teobert Maler.

Após as primeiras expedições arqueológicas de Sthephens e Catherwood e de seus seguidores, acima já citadas, inicia-se um novo seguimento de pesquisas: as grandes escavações realizadas por grandes empreendimentos de museus e universidades, o que proporcionou um maior rigor científico nas pesquisas. As primeiras escavações em grande escala foram realizadas pelo Museu Peabody de Arqueologia e Etnologia da Universidade de Harvard entre 1892 e 1915, com aproximadamente vinte expedições nesse período, seguida pela Instituição Carnegie de Washington, em 1915 e muitas outras (THOMPSON, 1984: 52-3), tendo como conseqüência uma visão 
mais ampla das estruturas dos sítios: templos, estelas (monumentos verticais de tamanhos variados que apresentavam registros escritos) e praças abertas.

Os resultados dessas escavações colaboraram para a elaboração dos primeiros trabalhos de síntese sobre Arqueologia maia, publicados entre os anos de 1900 e 1930, por pesquisadores como Hebert Spinden, Thomas Gann, Thomas Joyce, Sylvanus G. Morley e John Eric S. Thompson, os dois últimos são os maiores representantes do período com suas respectivas obras: The Ancient Maya e The Rise and Fall of Maya Civilization. Na opinião do revisionista Jeremy A. Sabloff, Thompson, Morley e seus colegas se impressionaram profundamente com os formidáveis feitos intelectuais e artísticos dos maias. Eles se dedicaram a documentar e a estudar os monumentos daquela civilização, principalmente as estelas, os grandes templos e os palácios encontrados as centenas pela Península de Yucatán. Assim se deixaram envolver por um ardente e fiel sentimento de amor e respeito por todas as coisas maias.

Sabloff sublinha ainda que, Thompson e Morley obtiveram enorme prestígio e influência por conseguirem sintetizar com grande sucesso suas próprias pesquisas e a de seus colegas, tornando seus 
Cadernos de Clio, Curitiba, n. ${ }^{\circ}$ 2, 2011

escritos predominantes e constituindo a base do que chamamos "modelo tradicional" dos antigos maias (SABLOFF, 1990: 22).

A formação desse modelo tradicional da arqueologia maia, acima referido por Sabloff, durou até meados do século XX, sendo o mais difundido nos livros didáticos, no ensino primário e fundamental. Este modelo apresentava a sociedade maia com uma descrição romântica, como percebemos nesse trecho de Thompson sobre os cultos maias:

(...) do mesmo modo em tempos antigo, se alguém chegava tarde a uma cerimônia, tinha que se esbarrar na multidão que, amontoada nas praças, presenciava atentamente os ritos que tinham lugar frente à entrada do templo, lá sobre a pirâmide. Fácil me pareceu ver em minha mente o sacerdote-astrônomo que, ansioso por comprovar suas teorias sobre a duração do ano solar, passava de uma a outra estela para ver que cálculos haviam registrado os colegas que o precederam no passado já distante (...) (THOMPSON, 1984: 22). ${ }^{1}$

\footnotetext{
${ }^{1} \mathrm{O}$ trecho citado foi traduzido por mim. A partir de agora todos os trechos traduzidos por minha iniciativa conterão a sigla T. L. A. (Tradução Livre do Autor). (...) del mismo modo en tiempos antiguos, si alguien llegaba tarde a una ceremonia, tenía que meter el hombro en la multitud que, arremolinada en las plazas, presenciaba atentamente los ritos que tenian lugar frente a la entrada del templo, allá sobre la pirámide. Fácil me pareció ver en mi mente al sacerdoteastrónomo que, ansioso por comprobar sus teorías sobre la duración del año solar o del mes lunar, pasaba de una a otra estela para ver qué cálculos habian registrado los colegas que le precedieron en el pasado ya distante(....).
}

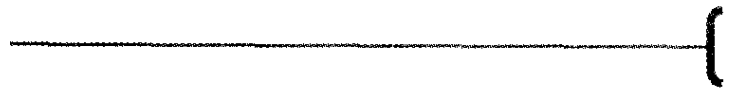


Cadernos de Clio, Curitiba, n. ${ }^{\circ} 2,2011$

\begin{abstract}
Os tradicionalistas também idealizavam essa civilização como única, de feitos inigualáveis, ao mesmo tempo em que buscavam pontos comuns com outros povos totalmente distintos, por exemplo, na tentativa de Thompson em relacionar o pensamento maia ao dos antigos atenienses:
\end{abstract}

A filosofia dos maias pode, em seus termos gerais, se comparar com a dos atenienses, já que a chave para a vida dos primeiros foi a "moderação em todas as coisas". A essa crença filosófica, entretanto, os maias adicionaram outros conceitos que são totalmente alheios ao pensamento ocidental. O tema supremo por excelência para os maias sempre foi o passo do tempo, é dizer, esse dilatado conceito do mistério da eternidade e a idéia, já mais estreita, da divisão do próprio tempo no que seriam suas equivalências dos séculos, anos, meses e dias. O ritmo do tempo, portanto, fascinou aos maias: o interminável fluxo dos dias deslizando-se da eternidade do futuro a essa eternidade do passado os maravilhava. Em seus textos hieroglíficos aparecem cálculos que chegam bem distante no passado; outros, em menor escala, são sondagens no futuro [...] (THOMPSON, 1984: 27) ${ }^{2}$.

${ }^{2}$ T. L. A. No original: La filosofia de los mayas puede, en sus términos generales, parangonarse con la de los atenienses, ya que la clave para la vida de los primeros fue la "moderación en todas las cosas". A ese credo filosófico, empero, los mayas añadieron otros conceptos que son totalmente ajenos al pensamiento occidental. El tema supremo por excelencia para los mayas siempre fue el paso del tiempo, es decir, ese dilatado concepto del misterio de la eternidad y la idea, más estrecha ya, de la división del proprio tiempo en lo que serian sus equivalencias de los siglos, los años, los meses y los días. El ritmo del tiempo, pues, fascinó a los mayas: el interminable flujo de los dias deslizándose de la eternidad del futuro a esa otra eternidad del pasado los marabillaba. En sus textos jeroglificos aparecen 
Um dos temas de discussão dos arqueólogos tradicionalistas era a origem da cultura maia e de outros povos da Mesoamérica, muitos acreditavam que os grupos humanos que cruzaram o estreito de Bering traziam consigo um mínimo de cultura, que os permitiu criar uma cultura nova. Porém, outros, ao comparar elementos culturais asiáticos semelhantes aos dos povos pré-colombianos, defendiam que esses grupos apenas recriaram seus valores no novo continente. Já Thompson defendia uma posição mediana entre esses dois pensamentos (THOMPSON, 1984: 65-6). Então para melhor compreender os avanços da cultura maia, os tradicionalistas dividiram a história maia em três períodos: pré-clássico ou formativo (1500 a.C. a 300 d.C.), clássico (300 d.C. a 900 d.C.) e pós-clássico (900 d.C. a 1520 d.C.).

O pré-clássico seria formado por pequenos grupos de camponeses, organizados em estruturas semelhantes a comunidades - que mais tarde teriam um papel fundamental no desenvolvimento das cidades - com arquitetura monumental incipiente. Todavia, Thompson acreditava que já no Formativo Tardio (500 a.C. a 100 d.C.) havia estratificação social, uma vez que no período se construía pequenos templos e outras pequenas obras e que a condição de

cálculos que llegan bastante lejos en el pasado; otros, en menor escala, son sondeos en el futuro[...]. 
existência destas edificações era a organização da massa camponesa a partir da submissão desta a uma pequena casta sacerdotal dirigente. Nas palavras do inglês, ao analisar um povoado que, no período, habitava a região da costa do Pacífico da atual Guatemala, ao leste da fronteira com o México:

É quase seguro que a gente do horizonte Ocós edificava montículos como bases para templos, o que vem a ser uma evidência de que, ainda naquela época agora tão remota, esses grupos humanos já estavam organizados em comunidades, e também de que começavam a ter uma estratificação social, posto que a construção dos embasamentos-templo implica a existência de uma casta sacerdotal, sustentada por niveis sociais que a aceitavam e a apoiavam (THOMPSON, 1984: 65) ${ }^{3}$.

Sobre o final do Formativo Tardio há certo consenso que foi o período em que apareceram as características principais da civilização maia, como os primeiros resquícios de escrita e de arte com forte influência da cultura de La Venta, também conhecida como cultura olmeca, que possuía grande habilidade com trabalhos

\footnotetext{
${ }^{3}$ T. L. A. No original: Es casi seguro que la gente del horizonte Ocós erigía monticulos como bases para templos, lo que viene a ser una evidencia de que, aun en aquella época ahora tan remota, esos grupos humanos ya estaban organizados en comunidades, y también de que empezaban a tener una estratificación social, puesto que la construcción de basamentos-templo implica la existencia de una casta sacerdotal, sostenida por niveles sociales que la aceptan y apoyan.
} 
esculturais em jade e em pedra, que provavelmente atingiu seu ápice entre 800 a 400 a.C. (THOMPSON, 1984: 68-70).

Já o período clássico seria marcado pelo esplendor econômico e cultural da civilização maia, com o desenvolvimento da escrita, da arquitetura, da astrologia e da arte refinada (vasos e cerâmicas policromados, jóias etc.). Entretanto os arqueólogos tradicionalistas acreditavam que não existira a formação de centros urbanos - as cidades eram centros de peregrinação onde à maioria da população só permanecia em datas religiosas -, pois estes centros eram habitados somente pelos sacerdotes, governantes e seus auxiliares, enquanto a grande massa camponesa, que alimentava toda a sociedade, se encontrava no campo dedicando-se integralmente a agricultura. Outro argumento dos tradicionalistas para a impossibilidade de se formar de centros urbanos está no fato de que eles acreditavam que a prática agrícola mais utilizada pelos maias era a coivara (slash-and-burn) - sistema de cultivo que consiste no desmatamento do terreno a partir do corte e limpeza do solo pela queima da vegetação seca -, o que agredia severamente o solo, não permitindo colheitas seguidas e criando a necessidade cíclica de buscar a cada safra novas áreas cultiváveis.

A religião, para Thompson, era motivo de preocupação constante para os povos maias, que sempre tentavam estabelecer uma 
Cadernos de Clio, Curitiba, n. ${ }^{\circ}$ 2, 2011

conexão entre o passado e o futuro, além de guiarem seus comportamentos pela sucessão diária de divindades (THOMPSON, 1984: 27-8). Esse modelo de reflexão se tornou sugestivo para que os arqueólogos tradicionalistas pensassem nos sacerdotes maias como detentores de grande poder sobre a população camponesa, ocasionando um regime teocrático, o que caracterizaria aquela sociedade como pacífica e homogênea - influência da corrente evolucionista em voga do período e da convivência com os descendentes maias modernos -, mesmo quando existiam evidências provando o contrário eles as ignoravam, como as pinturas em murais representando batalhas, como demonstra Morley:

Um importante fator que se deve levar em conta ao se reconstruir o tipo de governo dos maias da Época Clássica é a falta de guerras entre eles, o que se pode considerar como um indício da grande importância da religião e do governo. E tudo nos faz pensar que os sacerdotes de um culto religioso altamente organizado e dogmaticamente inflexível, governam a área central. É difícil dizer, entretanto, até que ponto a religião se introduziu nos assuntos da política, mas talvez a homogeneidade cultural e o isolamento da região maia, tenham reduzido ao mínimo a necessidade de um controle político (MORLEY, 1992: 160).

\footnotetext{
${ }^{4}$ T. L. A. No original: Un factor importante que se debe ser tomado en cuenta al reconstruir el tipo de gobierno de los mayas de la Época Clásica es la falta de guerra entre ellos, lo que puede considerarse como un indicio de la abrumadora importancia de la religión en el gobierno. $Y$ todo nos hace pensar que los sacerdotes de un culto religioso altamente organizado y dogmáticamente
} 
Cadernos de Clio, Curitiba, n. ${ }^{\circ} 2,2011$

Ao mesmo tempo em que aplicavam conceitos evolucionistas para justificar a suposta ausência de guerras, utilizavam o determinismo social, partindo dos problemas contemporâneos que presenciaram no convívio com os descendentes maias modernas, para explicar o motivo pelo qual esse povo não ter se restabelecido novamente como grande cultura (THOMPSON, 1984: 46-7). Acreditavam, também, que os sacerdotes dedicavam-se exclusivamente às previsões astrológicas a partir da observação e de cálculos ou da adivinhação. Os resultados dessas previsões eram anotados em tiras de papel ou de pele de veado, em inscrições feitas nas paredes dos templos, em vasos e nas estelas (NAVARRO, 2007: 23), assim relacionando essa escrita apenas às previsões astrológicas e a pensamentos religiosos de difícil compreensão.

Para esses primeiros arqueólogos outro importante fator que permitiu a realização de tais feitos pelos maias foi o suposto isolamento geográfico, como o proporcionado por suas florestas, que consolidou a homogeneidade da população e da cultura de uma ponta a outra de seu território (SABLOFF, 1990: 25-6).

Então, por volta do século IX, os maias entrariam em um acentuado processo de declínio econômico e cultural que os

inflexible, gobernaban el área central. Es dificil decir, sin embargo, hasta qué punto la religión se introdujo en los asuntos de la política, pero tal vez la homogeneidad cultural y el aislamiento de la región maya, haya reducido al mínimo la necesidad de un control político. 
tradicionalistas apontavam como resultado de catástrofes ambientais e pragas agrícolas, tais como terremotos, furacões e secas. Nota-se também a influência de teorias do período vivido pelos pesquisadores, como demonstra Alexandre G. Navarro: "O discurso assumido de que o colapso da civilização maia foi provocado por um levante camponês segue esta mesma linha de pensamento medievalista que esteve presente e predominou em seu tempo" (NAVARRO, 2008: 354). As cidades ao sul estariam em decadência, sendo desabitadas, enquanto se erguiam cidades ao norte da península de Yucatán, como o famoso exemplo do sítio de Chichén Itzá que após sua decadência permitiu a formação de uma confederação entre os centros maias, liderados por Mayapán. Porém, as cidades do norte da península acabaram no domínio e na influência de outros povos provenientes do centro do México, como os toltecas, resultando no pleno colapso da cultura maia, com o desaparecimento da escrita e das grandes obras.

Esse processo de queda das cidades do sul até as do norte marcou o período pós-clássico, predominando assim pequenos centros rivais entre si e sem a glória da época clássica, foi esse mundo indígena decadente que os espanhóis encontraram, no século XVI, no período da conquista (NAVARRO, 2007: 24). 
Cadernos de Clio, Curitiba, n. ${ }^{\circ}$ 2, 2011

Contudo, o advento do Carbono 14, em meados dos anos 1960, o surgimento de metodologias inovadoras de campo e de técnicas de laboratório transformaram o modo e o local de trabalho dos arqueólogos. Agora não mais restritos as trincheiras das escavações, os arqueólogos contemporâneos podem ser igualmente encontrados sentados nos terminais de computadores processando análises variadas de distribuição de artefatos encontrados no chão de uma caverna. Ou eles podem ser encontrados debruçados sobre microscópios binoculares examinando finas seções de cacos de cerâmica pré-histórica, ou inspecionando longas imagens de satélites a procura de sinais de cursos d'agua, ou utilizando a alta tecnologia de instrumentos topográficos a laser que mapeiam centros urbanos pré-industriais (SABLOFF, 1990: 2).

As inovações acima citadas também refletiram na maneira de pensar e de se estudar a civilização maia, pois os arqueólogos normativos ou tradicionais defendiam uma perspectiva que predominava na Antropologia Cultural da América baseada na partilha de idéias:

[...] De acordo com essa visão, todos os membros de uma cultura compartilhavam um modelo ideal mental que lhes era ensinado quando crianças. Essas idéias compartilhadas eram expressas na peculiaridade cultural e eram caracterizadas por uma longa lista dessas peculiaridades. Tais peculiaridades incluindo $o$ 
Cadernos de Clio, Curitiba, n. ${ }^{\circ} 2,2011$

modo que a cerâmica era feita e decorada, o método para construir casas, ou a natureza do mundo espiritual e as divindades popularizavam isso. A ênfase global estava na homogeneidade das culturas (SABLOFF, 1990: $7-8)^{5}$.

Enquanto os novos arqueólogos argumentavam que tal pensamento ignorava a variedade cultural, defendiam uma visão de sistemas e subsistemas culturais que se adaptavam e se modificavam ao longo do tempo e que os povos interagentes participavam cada um a sua maneira. A tarefa do maianista, portanto, consistia em relacionar o documento material com a identificação de subsistemas culturais e ao identificá-los tentar compreender quais eram suas respectivas ligações, assim procurando formar o todo, por exemplo:

[...] O subsistema tecnológico poderia consistir em trabalhadores, ferramentas, materiais e técnicas ligadas à exploração do ambiente, ao passo que os subsistemas econômicos e políticos poderiam estar encarregados na organização de tal exploração [...] (SABLOFF, 1990: $8)^{6}$.

\footnotetext{
${ }^{5}$ T. L. A. No original: [...] According to this view, all members of a culture shared an ideal mental template that they were taught as children. These shared ideas were expressed in cultural traits, and cultures were characterized by long lists of these traits. Such traits included the way pottery was made and decorated, the method for building houses, or the nature of the spiritual world and the deities populating it. The overall emphasis was on the homogeneity of cultures.

6 T. L. A. No original: [...]The technological subsytem(...) would consist of workers, tools, materials and techniques linked with exploitation of the environment, while economic and political subsystems would be in charge of organizing such exploitation [...].
} 
A adoção da perspectiva de subsistemas implicou em mudanças imediatas nos trabalhos de campo, pois esta revela a factual impossibilidade de escavação de um sítio completo e adotando a cultura como homogênea, não seria plausível a crença em grandes alterações entre um e outro ponto de escavação do sítio arqueológico, enquanto que a aceitação na variedade de sistemas necessita de uma análise mais crítica a respeito das amostras e do campo de escavação.

Auxiliados pelas tecnologias de campo e de laboratório e a partir dessa nova corrente de pensamento, os novos arqueólogos, por volta dos anos 1970, começaram a questionar a representabilidade do passado dos restos materiais, chegando então a dois pontos principais. $\mathrm{O}$ primeiro busca responder do que $\mathrm{o}$ vestígio arqueológico seria formado e que alterações ele sofreu - como o desgaste ao longo do tempo, a putrefação das partes perecíveis e mesmo a reutilização das peças por outras civilizações - até chegar a nossas mãos. $O$ segundo ponto tenta ligar o artefato presente ao seu uso no passado, às vezes, recorrendo a analogias com os descendentes modernos dos maias, como, por exemplo, ao encontrar numa escavação pedaços de pedras em toda extensão de uma cabana, o arqueólogo buscará pistas sobre o uso dessas pedras e ao deparar-se com os atuais camponeses da região notarão que estes utilizam as 
pedras para constituir a base de suas choupanas, o que os levará a pensar que os antigos maias também faziam o mesmo. Porém, o cuidado com o uso de comparações é redobrado para não repetirem os erros dos tradicionalistas que transformavam suas hipóteses por analogia em evidências factuais, como o fizeram ao reparem as feiras modernas da Guatemala e dessa observação inferiram que os espaços abertos nos pátios das cidades eram utilizados como mercados no passado, além de outras referências, como a do uso pelos antigos e modernos maias da, já referida, coivara (slash-and-burn) (SABLOFF, 1990: 12).

Assim, encorajando os pesquisadores maianistas a reformular os dados e as convenções anteriores a eles, Jeremy A. Sabloff se sobressaiu com um dos maiores ícones revisionistas. Um elemento fundamental para a revisão dos escritos tradicionais foi a decifração de grande parte da escrita hieroglífica que possibilitou demonstrar que os maias não se preocupavam apenas da religião e da astrologia - mas também da guerra, os feitos políticos, o registro das dinastias que ocuparam o poder, entre outros - o que colaborou para a melhor compreensão daquela sociedade e das crenças que seguiam.

Para os revisionistas, o período pré-clássico (recua do ano 800 a.C. e dura até aproximadamente 300 a.C.) é marcado pela ocupação do território maia, pelo crescimento da população - que 
viabilizou a concentração de mão-de-obra necessária para construção das primeiras obras públicas e para alimentar a elite que surgia -, pela formação das primeiras cidades e pelas guerras (derrubando a teoria de sociedade pacífica a partir da descoberta de sulcos e trincheiras artificiais para proteção de algumas cidades). No período pré-clássico tardio já se fala até em rotas comerciais, desmistificando a idéia de homogeneidade cultural, que no clássico levaram os maias a terem relações comerciais com diferentes povos entre a costa norte da América do Sul até a costa sudeste dos Estados Unidos.

Graças às novas tecnologias, os revisionistas conseguiram formular novas pesquisas e novas hipóteses sobre o desenvolvimento do comércio maia. Como pontua Sabloff ao demonstrar que os antigos arqueólogos maianistas, podiam escavar um sítio nas tropicais terras baixas da Península de Yucatán e possivelmente encontrar pedaços de obsidiana (resina vulcânica muito cortante) em suas trincheiras. Ao comparar esses artefatos com outros similares de diversas regiões da área maia, podiam concluir que, a partir da forma de suas lâminas e de seus gumes afiados, eram utilizados para cortar. Os tradicionalistas também podiam apontar que a carência de vulcões nas terras baixas refletiria na necessidade de comércio com as terras altas. Entretanto, Sabloff nos mostra que os arqueólogos maianistas de hoje podem ir muito além. Usando novas técnicas químicas, os 
arqueólogos modernos podem apontar exatamente em que lugar das terras altas os pedaços de obsidiana derivam. Dependendo das questões específicas levantadas pela pesquisa, eles podem cuidadosamente peneirar e examinar a terra escavada a procura de lascas que podem revelar se as ferramentas foram comercializadas ou se foram manufaturadas no próprio sítio. Os novos arqueólogos podem examinar a área da descoberta e observar se as ferramentas de obsidiana são encontradas em locais domésticos, e, caso forem, se são apenas encontradas nas residências da elite ou também nas residências dos camponeses. Eles podem medir a largura e o comprimento das lâminas e compará-las com outras de outros sítios das terras baixas para analisar se o tamanho das lâminas mudava conforme aumentava a distância em relação à fonte das terras altas. Além das variações por distância geográfica, podem procurar mudanças no passar dos anos. Essas e outras análises também podem ser usadas para testar diferentes hipóteses sobre onde as rotas de comércio começaram e até onde foram, como eram controladas, e se modificavam através do tempo. Toda essa investigação se constitui em uma parte de uma estratégia mais geral focada no entendimento da natureza da civilização maia - nesse caso, nos aspectos econômicos e políticos - e como e por que essa natureza evoluiu por séculos de desenvolvimento (SABLOFF, 1990: 6-7). 
Os recentes estudos também nos apontam que o período clássico teria durado entre 300 a.C. a 1250 d.C. e o pós-clássico de 1250 d.C. a 1525 d.C., pois as cidades situadas ao sul declinavam economicamente ao mesmo tempo em que as cidades ao norte da península de Yucatán ascendiam. Todavia, o discurso de dominação das cidades do norte por outros povos foi desmistificado a partir da análise com carbono 14 de artefatos de madeira descobertos em Chichén Izá que datam dois séculos antes do florescimento de Tula, capital dos toltecas. Além de não existir nenhum resquício da arquitetura tolteca naquela cidade maia, pois é de se presumir que se a cidade fosse tomada, o dominador utilizaria sua própria arquitetura em novas construções. Fala-se em um contato entre as diferentes culturas, pressupondo, desta forma, as relações comerciais aqui já mencionadas.

Com as imagens feitas pelo satélite descobriu-se também que os maias não praticavam apenas a coivara, eles tinham grande capacidade de moldar o ambiente de acordo com suas necessidades: elevaram terrenos para evitar alagamentos, desviavam o curso de rios para irrigar locais mais áridos, além de proporcionar uma recarga do solo pelos nutrientes trazidos pelas águas dos rios, o que possibilitou o aumento da produção de alimentos e o conseqüente aumento populacional. Entretanto, para os revisionistas, houve um 
crescimento desproporcional da elite maia, que não foi acompanhado pelo crescimento da população camponesa, assim o aumento na demanda por alimentos não foi acompanhado pelo crescimento da mão-de-obra - como mostra as análises de alguns fósseis humanos do período que apresentavam um quadro de desnutrição - o que provavelmente gerou conflitos e mais guerras. Outros estudos demonstram que houve um grande desmatamento da floresta tropical, acompanhado por grandes erosões, o que provavelmente interferiu em fatores climáticos e no ciclo agrícola, assim a complexa sociedade maia ruía, restando apenas alguns pequenos e fragmentados povoados agrícolas até a chegada dos conquistadores espanhóis.

\section{Conclusão}

No texto aqui apresentado procurei esboçar de maneira clara e coerente um panorama geral da breve produção historiográfica que tive contato sobre a civilização maia, partindo da perspectiva arqueológica. Deve-se postular que os estudos desta civilização são recentes e ainda mais limitados no Brasil, pois a abordagem do tema muitas vezes se esbarra na ausência de bibliografia e na dificuldade de acessarmos os campos de escavação, o que exigirá do pesquisador 
um enorme esforço para abordar seu tema de investigação nos pormenores.

\section{Bibliografia}

NAVARRO, A. G. Reis na floresta tropical? Novas teorias sobre a civilização maia ISSN 0101-8515. Ciência Hoje, v. 40, p. 18-27, 2007.

NAVARRO, A. G. A civilização maia: contextualização historiográfica e arqueológica ISSN 0101-9074. História (UNESP. Impresso) (Cessou em 2004), v. 27, p. 347-377, 2008.

MORLEY, S. G. La civilizacion maya. Mexico, D.F.: Fondo de Cult. Economica, 1992.

SABLOFF, J. A. The New Archaeology and the ancient maya. Nova Iorque, Scientific American Library, 1994.

THOMPSON, J. E. S. Grandeza y decadencia de los mayas. Mexico, D.F: Fondo de Cult. Economica, 1984. 